\title{
TRACE ELEMENTS IN SOILS IN THE NORTHERN AND THE CENTRAL TIAN-SHAN (KAZAKHSTAN - KYRGYZSTAN)
}

L. Šefrna, F. Previtali, R. Comolli, D. Cantelli, M. Zdravkovi č: Trace elements in soils in the northern and the central Tian-shan (KazakhstanKyrgyzstan). - Geografie-Sborník CGS, 113, 3, pp. 253-268 (2008). - The present paper examines and compares heavy metal contents in soils from two altitudinal sequences in the northern and the central Tian-Shan mountains. The soil horizons of 11 sites were described, sampled, analysed, interpreted and classified. Results show that pedological processes similar to those responsible for the development of steppe chernozems are active even at very high elevations. This is probably in part due to the presence of blankets of aeolian silt deposited recently and in the past.

In order to verify the degree of accumulation and possible ecotoxicity, the distribution and mobility of $\mathrm{Cd}, \mathrm{Cr}, \mathrm{Cu}, \mathrm{Zn}, \mathrm{Pb}$, and $\mathrm{Ni}$ within soil profiles were checked. Relationships among elements and other pedological parameters, such as organic carbon content, $\mathrm{pH}$, texture, etc., were investigated. Lastly, the possible risk of contamination was assessed.

KEY WORDS: trace elements - soils - Tian-Shan - taxonomy.

\section{Introduction}

Soil profiles situated northwest and east-southeast of Lake Issyk-Kul (Fig. 1) in the central Tian-Shan mountains (Kazakhstan and Kyrgyzstan) were investigated. Two previous works (Comolli et al. 2003, Previtali et al. 1997) discussed findings on relationships among soils, climatic conditions, vegetation cover and landforms.

This work examines the soil content of trace elements considered to be good indicators of possible soil contamination at high altitudes $(2,000-3,000 \mathrm{~m}$ a. s. l.), which is often due to atmospheric contributions. Trace element contents in high altitude glaciers and soils from various parts of the world are often higher than expected. This is due to the fact that atmospheric transport and fallout bring human-induced pollution to regions even very distant from the source.

\section{Geography, Geology and Geomorphology}

The Tian-Shan mountain belt extends for about $2,500 \mathrm{~km}$ from the Syrdarja River basin in the west to the Gobi Desert in the east. The belt is characterised by several parallel E-W-trending mountain systems, with elevations frequently exceeding $5,000 \mathrm{~m}$. The mountain system is about 600 


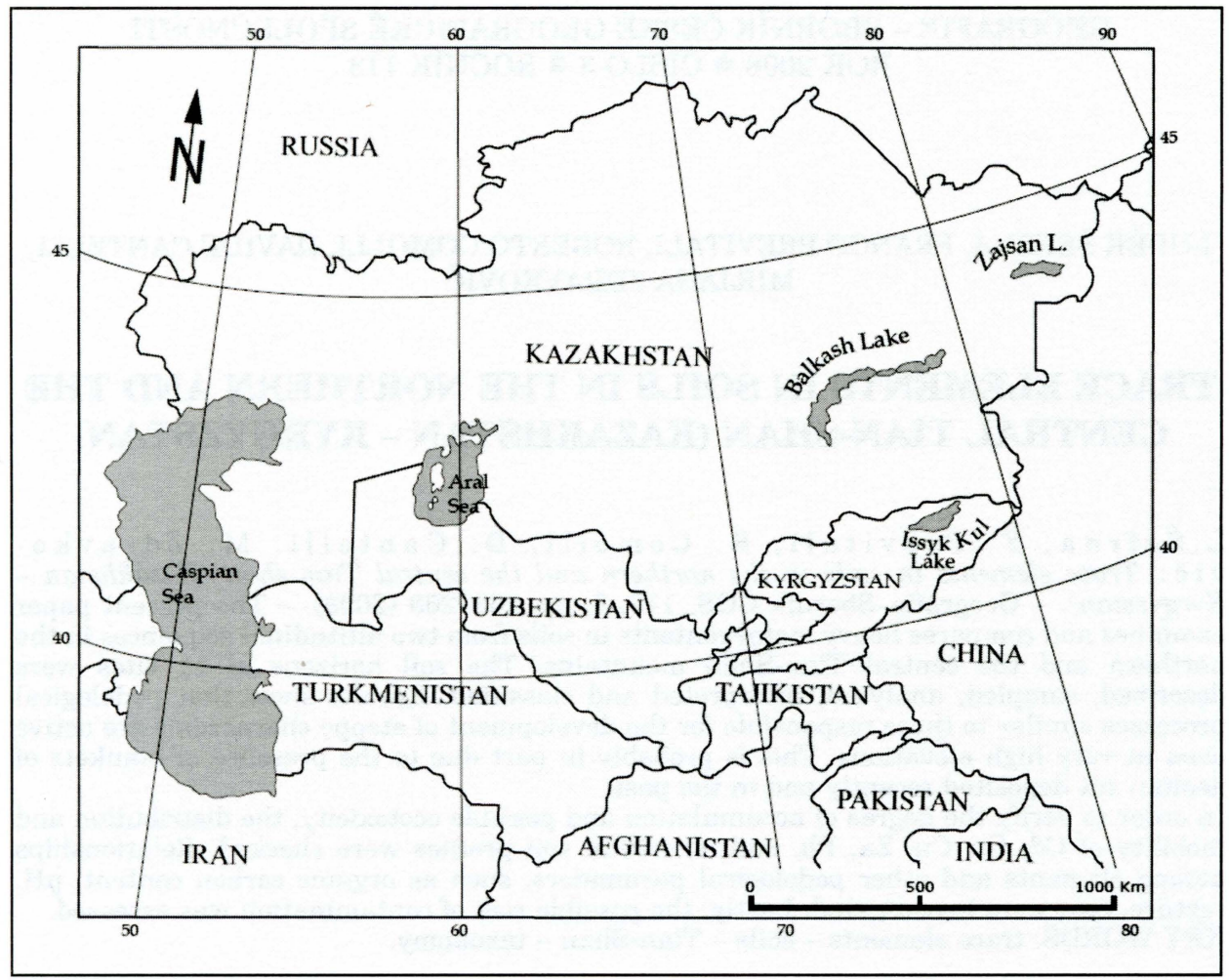

Fig. 1 - Geographic location of the study area

$\mathrm{km}$ wide from the northern Kazakh shield to the southern Tarim block. Between 2,000 and 3,000 $\mathrm{m}$ a. s. l., ridges are separated by depressions either partially filled with glacial, fluvioglacial and alluvial deposits or occupied by lakes (e.g., Alma-Atijnskoe Ozero). The major rivers in this region, the Čylyk and Čn-Kemin, flow respectively to the east and west and have their sources in the area between the Zailijskij Alatau and the Kjungej Ala-Too ranges.

Soils, their forming factors and geochemical load along two transects were investigated between latitudes $42^{\circ} 10^{\prime} \mathrm{N}$ and $43^{\circ} 10^{\prime} \mathrm{N}$ and longitudes $76^{\circ} 45^{\prime} \mathrm{E}$ and $78^{\circ} 32^{\prime} \mathrm{E}$. Soil sites are situated at altitudes ranging between $\mathrm{m} 2,000$ and m 3,500 a. s. 1 .

Two different physiographic districts, located respectively south of the town of Alma-Ata and south of Prževal'sk, were identified (Figures 2 and 3):

- the Northern District (north of Lake Issyk-Kul)

- the Eastern District (east of the lake).

In the Northern District, to the south of Alma-Ata, the Quaternary loess cover and glaciofluvial deposits extend over large areas. The loess mantle is in places up to $20-30 \mathrm{~m}$ thick. Devonian granites and granodiorites constitute the near mountain chains (Ministry of Geology of SSSR 1983, Abdulin et al. 1984). Around Lake Alma-Atijnskoe, Ordovician gabbros and norites are associated with granites (Tibaldi et al. 1997).

Further south, having crossed the watershed, in the Kyrgyz Republic, several large faults mark a sharp lithological change from igneous formations 


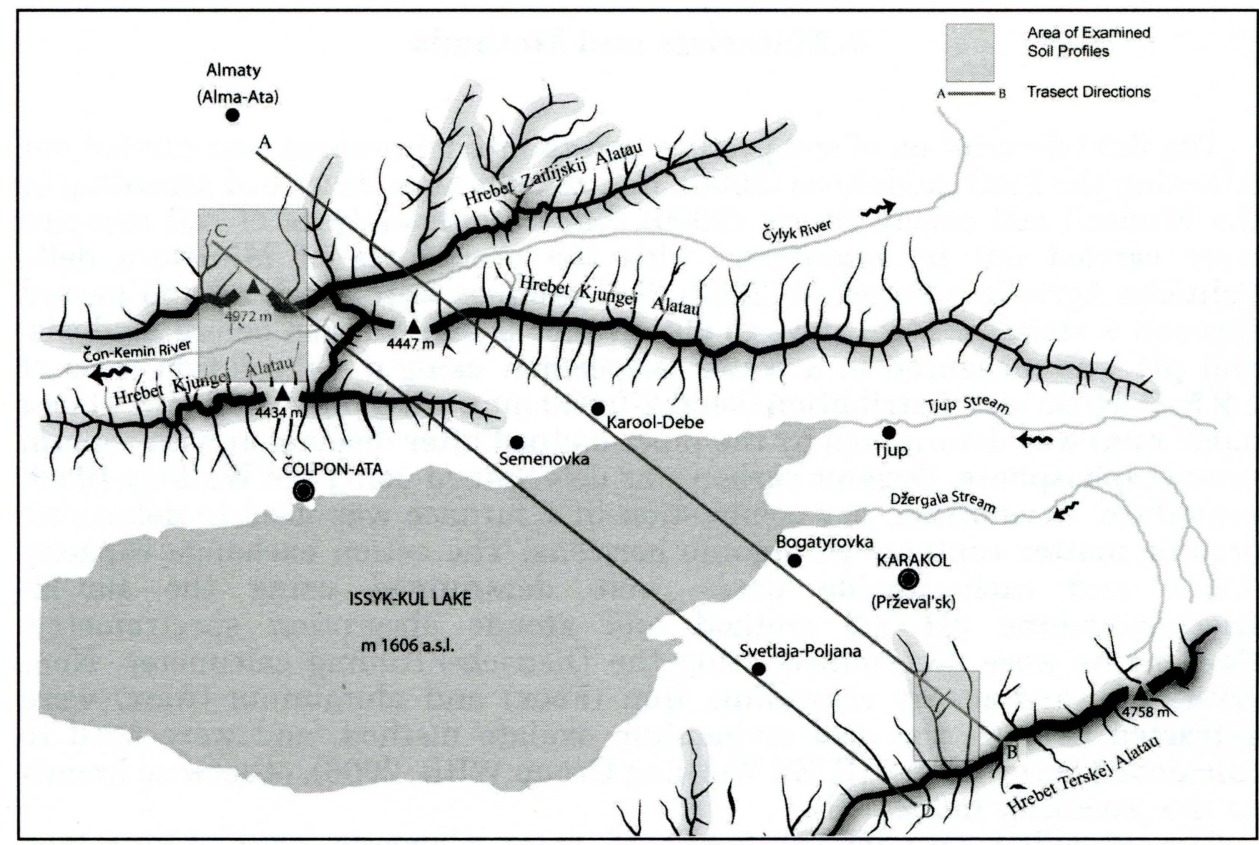

Fig. 2 - Major mountain ranges and rivers in the investigated area. A-B and C-D are the transect directions

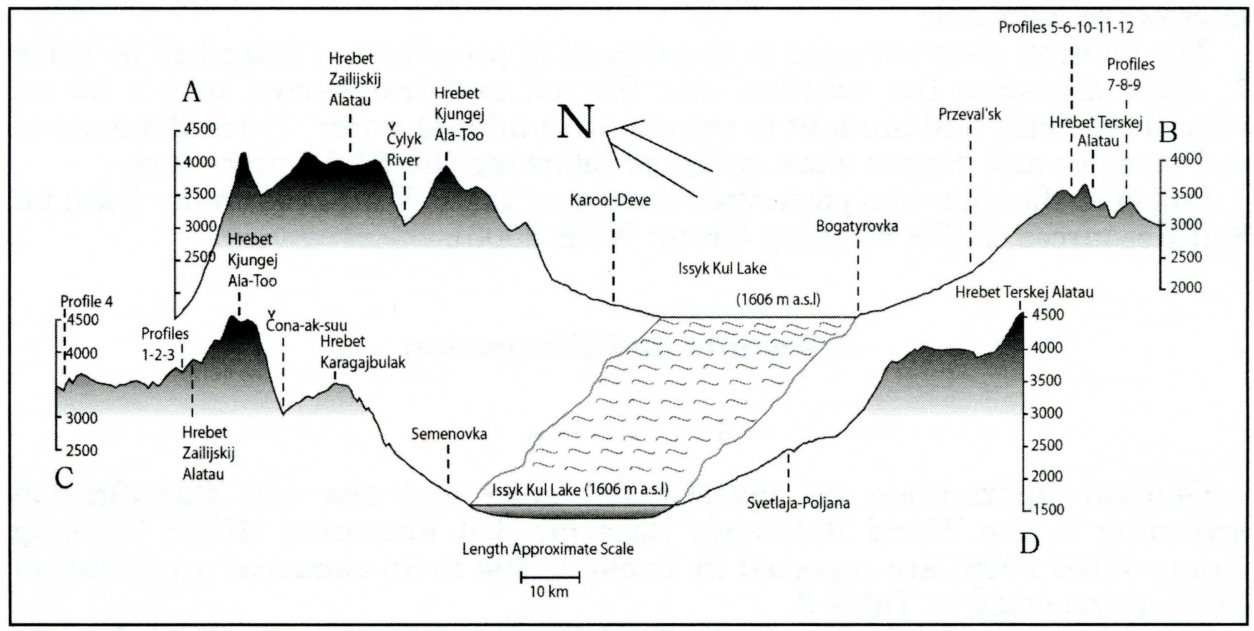

Fig. 3 - Cross sections A-B and C-D showing the location of soil profiles

to sedimentary (mainly sandstones and conglomerates) and metamorphic (phyllites, slates, greenschists, amphibolites) ones.

In the Eastern District, near Prževal'sk, the Tertiary sedimentary formations dominate, while further south deep faults place them in spatial continuity with Precambrian and Palaeozoic igneous masses (granodiorites, granites, and gabbros) locally alternating with metamorphic, extrusive igneous and carbonate rocks. 


\section{Materials and Methods}

The field description of soil profiles and their environment was carried out following the FAO guidelines (2006). Soil colours were described according to the Munsell soil colour charts (2000). Laboratory analyses of soil samples were carried out in accordance with the procedures of Ministero delle Politiche Agricole e Forestali (2000). Soil samples were air-dried and passed through a stainless steel sieve to obtain the $<2 \mathrm{~mm}$ fraction before analysis. Soil $\mathrm{pH}$ was measured in a water suspension using a soil:solution ratio of 1:2.5. Particle size distribution (sand 2-0.050 mm, silt $0.050-0.002 \mathrm{~mm}$, clay < $0.002 \mathrm{~mm}$ ) was determined by the pipet method after dispersion with sodium exametaphosphate. Organic carbon was determined using the Walkley-Black procedure. In addition, dry combustion in a furnace was used to determine organic matter contents in organic horizons. The cation exchange capacity (CEC) and exchangeable bases were determined using the $\mathrm{BaCl} 2$ triethanolamine $\mathrm{pH} 8.2$ method and atomic absorption spectrometry. Carbonates were determined using the Dietrich-Frühling calcimeter. Noncrystalline and poorly crystalline iron (Feox) and aluminium (Alox) were extracted through the acid ammonium oxalate method, and were used to calculate Alox+1/2 Feox (IUSS Working Group WRB, 2006), otherwise known as the "spodicity index“ (SI).

The so-called pseudototal forms of trace elements were determined following the Bettinelli et al. (2000) procedure. About $250 \mathrm{mg}$ of sample were transferred into microwave vessels with $8 \mathrm{ml}$ of aqua regia and placed into the microwave carousel.

The heating program used in this digestion procedure is described in Table 1. After digestion the solution was filtered and transferred into a $50 \mathrm{ml}$ volumetric flask and brought to volume with milli-Q water. Trace elements in soil samples and blanks were analysed following the FAAS procedure.

Soil classification was performed according to the World Reference Base for Soil Resources (IUSS Working Group WRB 2006).

\section{Results and Discussion}

\subsection{Soils}

General information on investigated sites and the soil classification according to the World Reference Base for Soil Resources (IUSS Working Group WRB 2006) are reported in Table 2. The main chemical properties of soils are reported in Table 3.

Survey data and laboratory results indicate that Quaternary soil forming processes similar to the melanization responsible for the development of modern steppe-chernozems are active even at very high elevations. Such processes seem Tab. 1 - Heating program for microwave digestion

\begin{tabular}{|l|c|c|c|}
\hline Step & 1 & 2 & 3 \\
\hline Power (Watt) & 250 & 400 & 500 \\
Hold time (min) & 2 & 2 & 10 \\
\hline
\end{tabular}
to be most likely enhanced by the presence of both loess-like aeolian covers and particular climatic conditions (Comolli et al. 2003, Previtali et al. 1997).

On the contrary, in both surveyed districts, the B horizons 
Tab. 2 - Soil profile location, environmental data and soil classification

\begin{tabular}{|c|c|c|c|c|c|c|}
\hline \multicolumn{7}{|c|}{ NORTHERN DISTRICT } \\
\hline Profile & Location & $\begin{array}{c}\text { Elevation } \\
\text { m a.s. } 1 .\end{array}$ & Aspect & $\begin{array}{c}\text { Slope } \\
(\%)\end{array}$ & $\begin{array}{l}\text { Classification } \\
\text { (WRB 2006) }\end{array}$ & Parent material \\
\hline No. 1 & $\begin{array}{l}\text { Ak-Su Stream } \\
42^{\circ} 53^{\prime} \mathrm{N} \\
77^{\circ} 05^{\prime} \mathrm{E}\end{array}$ & 3,140 & $\mathrm{E}$ & $3-4$ & $\begin{array}{l}\text { Haplic Regosol } \\
\text { (Eutric, Gelic) }\end{array}$ & $\begin{array}{l}\text { Bouldery, pebbly } \\
\text { and loamy } \\
\text { diamicton over } \\
\text { schist debris }\end{array}$ \\
\hline No. 2 & $\begin{array}{l}\text { Čong-Kemin River } \\
42^{\circ} 54^{\prime} \mathrm{N} \\
77^{\circ} 03^{\prime} \mathrm{E}\end{array}$ & 2,980 & $360^{\circ}$ & Level & $\begin{array}{l}\text { Haplic Phaeozem } \\
\text { (Silty) }\end{array}$ & $\begin{array}{l}\text { Alluvial deposit, } \\
\text { buried by aeolian } \\
\text { material }\end{array}$ \\
\hline No. 3 & $\begin{array}{l}\text { Prahodnaia } \\
\text { Stream } \\
43^{\circ} 03^{\prime} \mathrm{N} \\
76^{\circ} 55^{\prime} \mathrm{E}\end{array}$ & 2,160 & $\mathrm{~W}$ & $80-100$ & $\begin{array}{l}\text { Haplic Cambisol } \\
\text { (Eutric) }\end{array}$ & $\begin{array}{l}\text { Igneous rock } \\
\text { debris and } \\
\text { diamicton }\end{array}$ \\
\hline \multicolumn{7}{|c|}{ EASTERN DISTRICT } \\
\hline No. 4 & $\begin{array}{l}\text { South of Prževal'sk, } \\
\text { Karakol Stream } \\
42^{\circ} 19^{\prime} \mathrm{N} \\
78^{\circ} 26^{\prime} \mathrm{E}\end{array}$ & 2,755 & $\mathrm{SE}$ & 80 & $\begin{array}{l}\text { Phaeozem } \\
\text { (Skeletic, Arenic) }\end{array}$ & $\begin{array}{l}\text { Granite and marble } \\
\text { talus deposit }\end{array}$ \\
\hline No. 5 & $\begin{array}{l}\text { South of Prževal'sk, } \\
\text { Karakol Stream } \\
42^{\circ} 19^{\prime} \mathrm{N} \\
78^{\circ} 27^{\prime} \mathrm{E}\end{array}$ & 2,850 & $\mathrm{~N}$ & 70 & $\begin{array}{l}\text { Haplic Phaeozem } \\
\text { (Pachic, } \\
\text { Episkeletic) }\end{array}$ & $\begin{array}{l}\text { Slate debris of } \\
\text { alluvial fan, buried } \\
\text { by aeolian silt }\end{array}$ \\
\hline No. 6 & $\begin{array}{l}\text { South of Prževal'sk, } \\
\text { Kol-Ter Stream } \\
42^{\circ} 17^{\prime} \mathrm{N} \\
78^{\circ} 31^{\prime} \mathrm{E}\end{array}$ & 3,455 & $\mathrm{NE}$ & 40 & $\begin{array}{l}\text { Mollic Leptosol } \\
\text { (Humic, Gelic) }\end{array}$ & $\begin{array}{l}\text { Silty loam } \\
\text { colluvial mudflow } \\
\text { over solid granite, } \\
\text { buried by aeolian } \\
\text { silt }\end{array}$ \\
\hline No. 7 & $\begin{array}{l}\text { South of Prževal'sk, } \\
\text { Uyun-Ter Stream } \\
42^{\circ} 13^{\prime} \mathrm{N} \\
78^{\circ} 30^{\prime} \mathrm{E}\end{array}$ & 3,600 & SSE & 10 & $\begin{array}{l}\text { Haplic Regosol } \\
\text { (Eutric, Gelic) }\end{array}$ & $\begin{array}{l}\text { Bouldery sandy } \\
\text { loam ancient } \\
\text { diamicton, buried by } \\
\text { aeolian silt }\end{array}$ \\
\hline No. 8 & $\begin{array}{l}\text { South of Prževal'sk, } \\
\text { Uyun-Ter Stream } \\
42^{\circ} 14^{\prime} \mathrm{N} \\
78^{\circ} 31^{\prime} \mathrm{E}\end{array}$ & 3,600 & NW & 15 & $\begin{array}{l}\text { Haplic Regosol } \\
\text { (Eutric, Gelic) }\end{array}$ & $\begin{array}{l}\text { Recent bouldery } \\
\text { diamicton }\end{array}$ \\
\hline No. 9 & $\begin{array}{l}\text { South of Prževal'sk, } \\
\text { Karakol Stream } \\
42^{\circ} 19^{\prime} \mathrm{N} \\
78^{\circ} 29^{\prime} \mathrm{E}\end{array}$ & 2,450 & $360^{\circ}$ & Level & $\begin{array}{l}\text { Gleyic Mollic } \\
\text { Fluvisol (Humic, } \\
\text { Endoskeletic) }\end{array}$ & Alluvial deposits \\
\hline No. 10 & $\begin{array}{l}\text { South of Prževal'sk, } \\
\text { Karakol Stream } \\
42^{\circ} 19^{\prime} \mathrm{N} \\
78^{\circ} 28^{\prime} \mathrm{E}\end{array}$ & 2,470 & $\mathrm{~W}$ & 80 & $\begin{array}{l}\text { Haplic Regosol } \\
\text { (Humic, Eutric) }\end{array}$ & $\begin{array}{l}\text { Crystalline schists } \\
\text { and serpentinites } \\
\text { talus deposit }\end{array}$ \\
\hline No. 11 & $\begin{array}{l}\text { South of Prževal'sk, } \\
\text { Karakol Stream } \\
42^{\circ} 19^{\prime} \mathrm{N} \\
78^{\circ} 27^{\prime} \mathrm{E}\end{array}$ & 2,695 & $\mathrm{E}$ & 70 & $\begin{array}{l}\text { Haplic Cambisol } \\
\text { (Humic, Eutric) }\end{array}$ & $\begin{array}{l}\text { Crystalline rocks } \\
\text { talus deposit }\end{array}$ \\
\hline
\end{tabular}


Tab. 3 - Main chemical properties of soils

\begin{tabular}{|c|c|c|c|c|c|c|c|c|c|c|c|c|}
\hline \multicolumn{13}{|c|}{ NORTHERN DISTRICT } \\
\hline \multirow[t]{2}{*}{ Profile } & \multirow[t]{2}{*}{ Horizon } & \multirow{2}{*}{$\begin{array}{c}\text { Depth } \\
(\mathrm{cm})\end{array}$} & \multirow{2}{*}{$\begin{array}{l}\text { Colour } \\
\text { (moist) }\end{array}$} & \multirow{2}{*}{$\underset{\left(\mathrm{H}_{2} \mathrm{O}\right)}{\mathrm{pH}}$} & \multirow{2}{*}{$\underset{(\%)}{\mathrm{CaCO}_{3}}$} & \multirow{2}{*}{$\underset{(\%)}{\text { Org. }} \mathrm{C}$} & \multirow{2}{*}{$\begin{array}{l}\text { O. M. } \\
(\%)\end{array}$} & \multirow{2}{*}{$\begin{array}{c}\mathrm{CEC} \\
\left(\mathrm{cmol}^{+}\right. \\
\left.\mathrm{kg}^{-1} \mathrm{soil}\right)\end{array}$} & \multirow{2}{*}{$\begin{array}{c}\text { Spodi-city } \\
\text { Index } \\
(\%)\end{array}$} & \multicolumn{3}{|c|}{ Particle size distribution } \\
\hline & & & & & & & & & & $\begin{array}{l}\text { sand } \\
(\%)\end{array}$ & $\begin{array}{l}\text { silt } \\
(\%)\end{array}$ & $\begin{array}{l}\text { clay } \\
(\%)\end{array}$ \\
\hline \multirow[t]{3}{*}{ No. 1} & $\mathrm{Ah}$ & $0-10$ & $10 \mathrm{YR}$ & 6.5 & 0.0 & 6.6 & & 37.8 & 0.62 & 28 & 63 & 9 \\
\hline & BA & $10-40$ & $10 \mathrm{YR}$ & 6.6 & 0.0 & 2.8 & & 35.6 & 0.71 & 21 & 65 & 14 \\
\hline & $\mathrm{C} / \mathrm{R}$ & $40-50+$ & & & & & & & & & & \\
\hline \multirow[t]{3}{*}{ No. 2} & A & $0-20$ & $10 \mathrm{YR}$ & 6.0 & 0.0 & 3.8 & & 47.0 & 0.75 & 19 & 57 & 24 \\
\hline & $\mathrm{AC}$ & $20-60$ & $10 \mathrm{YR}$ & 6.4 & 0.0 & 1.2 & & 39.1 & 0.62 & 26 & 59 & 15 \\
\hline & $2 \mathrm{C}$ & $60-80+$ & $3 / 3$ & & & & & & & & & \\
\hline \multirow[t]{4}{*}{ No. 3} & $\mathrm{Oe}$ & $5-0$ & $10 \mathrm{YR}$ & & & & & & & & & \\
\hline & $\mathrm{Ah}$ & $0-10 / 15$ & $10 \mathrm{YR}$ & 5,7 & 0.0 & 4.8 & & 27.8 & 0.34 & 47 & 38 & 15 \\
\hline & BA & $10 / 15-$ & $10 \mathrm{YR}$ & 5.9 & 0.0 & 0.7 . & & 9.1 & 0.21 & 40 & 22 & 8 \\
\hline & $\mathrm{C}$ & $\left|\begin{array}{c}20 / 30 \\
25 / 30-50+\end{array}\right|$ & & & 0.0 & & & & & & & \\
\hline \multicolumn{13}{|c|}{ EASTERN DISTRICT } \\
\hline \multirow[t]{6}{*}{ No. 4} & Ah1 & $0-9$ & $10 \mathrm{YR}$ & 5.9 & 0.5 & 12.5 & & 63.8 & 0.31 & 63 & 31 & 6 \\
\hline & Ah2 & $9-15$ & $10 \mathrm{YR}$ & 6.0 & 0.0 & 9.2 & & 56.5 & 0.38 & 53 & 38 & 9 \\
\hline & $2 \mathrm{~A}$ & $15-38$ & $\begin{array}{l}2 / 2 \\
10 \mathrm{YR}\end{array}$ & 5.9 & 0.2 & 2.1 & & 30.9 & 0.35 & 26 & 55 & 19 \\
\hline & $2 \mathrm{Bw}$ & $38-58$ & $\begin{array}{l}3 / 2 \\
10 \mathrm{YR}\end{array}$ & 5.8 & 0.7 & 0.6 & & 19.6 & 0.20 & 59 & 29 & 12 \\
\hline & & $58-75+$ & $\begin{array}{l}4 / 3.5 \\
10 Y R\end{array}$ & & & 04 & & & & 39 & 43 & 18 \\
\hline & & & $5 / 3$ & & & & & & 0.11 & כy & 40 & 10 \\
\hline \multirow[t]{7}{*}{ No. 5} & $\mathrm{Oi}$ & $0.5-0$ & & & & & & & & & & \\
\hline & $\mathrm{Oe}$ & $0-3$ & $\begin{array}{l}10 \mathrm{YR} \\
3 / 2\end{array}$ & 5.5 & 0.6 & & 65.3 & & 0.27 & & & \\
\hline & $\mathrm{Oa}$ & $3-6$ & 10YR & 5.4 & 1.4 & & 50.3 & & 0.42 & & & \\
\hline & Ah1 & $6-12$ & $\begin{array}{c}10 \mathrm{YR} \\
2 / 2\end{array}$ & 5.7 & 0.6 & 13.6 & & 74.0 & 0.42 & 14 & 75 & 11 \\
\hline & 2Ah2 & $12-40$ & $10 \mathrm{YR}$ & 6.5 & 0.9 & 6.6 & & 50.4 & 0.25 & 50 & 45 & 5 \\
\hline & $2 \mathrm{AC}$ & $40-55$ & 10YR & 7.2 & 0.1 & 2.1 & & 15.7 & & & & \\
\hline & $2 \mathrm{C}$ & $55-75+$ & $\begin{array}{c}\text { 1/S } \\
4 / 2 \\
4 / 2\end{array}$ & & & & & & & & & \\
\hline \multirow[t]{4}{*}{ No. 6} & $\begin{array}{l}\mathrm{Oi} \\
\mathrm{Oa}\end{array}$ & $\begin{array}{c}0.5-0 \\
0-2\end{array}$ & $\begin{array}{c}10 \mathrm{YR} \\
2 / 2\end{array}$ & 5.8 & 0.8 & & 51.2 & & 0.27 & & & \\
\hline & $\mathrm{Ah}$ & $2-4$ & $\begin{array}{c}10 \mathrm{YR} \\
3 / 3\end{array}$ & 5.5 & 0.0 & 8.0 & & 41.1 & & 33 & 62 & 5 \\
\hline & $\mathrm{AB}$ & $4-24$ & $10 \mathrm{YR}$ & 5.2 & 0.0 & 2.6 & & 26.2 & 0.41 & 19 & 72 & 9 \\
\hline & $2 \mathrm{R}$ & $24-45+$ & & & & & & & & & & \\
\hline \multirow[t]{2}{*}{ No. 7} & $\begin{array}{l}\mathrm{Oi} \\
\mathrm{Oa}\end{array}$ & $\begin{array}{c}0.5-0 \\
0-3\end{array}$ & $\begin{array}{c}10 \mathrm{YR} \\
2 / 2\end{array}$ & 6.1 & 0.6 & & 68.1 & & 0.13 & & & \\
\hline & $\mathrm{Ah}$ & $3-6$ & $\begin{array}{l}10 \mathrm{YR} \\
2.5 / 2\end{array}$ & 5.7 & 0.0 & 13.4 & & 67.5 & & 62 & 36 & 2 \\
\hline
\end{tabular}


Tab. 3 - Main chemical properties of soils

\begin{tabular}{|c|c|c|c|c|c|c|c|c|c|c|c|c|}
\hline \multirow[t]{2}{*}{ Profile } & \multirow[t]{2}{*}{ Horizon } & \multirow{2}{*}{$\begin{array}{c}\text { Depth } \\
\text { (cm) }\end{array}$} & \multirow{2}{*}{$\begin{array}{l}\text { Colour } \\
\text { (moist) }\end{array}$} & \multirow{2}{*}{$\begin{array}{c}\mathrm{pH} \\
\left(\mathrm{H}_{2} \mathrm{O}\right)\end{array}$} & \multirow{2}{*}{$\begin{array}{c}\mathrm{CaCO}_{3} \\
(\%)\end{array}$} & \multirow{2}{*}{$\underset{(\%)}{\text { Org. C }}$} & \multirow{2}{*}{$\begin{array}{l}\text { O. M. } \\
(\%)\end{array}$} & \multirow{2}{*}{$\begin{array}{c}\mathrm{CEC} \\
\left(\mathrm{cmol}^{+}\right. \\
\left.\mathrm{kg}^{-1} \mathrm{soil}^{+}\right)\end{array}$} & \multirow{2}{*}{$\begin{array}{c}\text { Spodi-city } \\
\text { Index } \\
(\%)\end{array}$} & \multicolumn{3}{|c|}{ Particle size distribution } \\
\hline & & & & & & & & & & $\begin{array}{c}\text { sand } \\
(\%)\end{array}$ & $\begin{array}{l}\text { silt } \\
(\%)\end{array}$ & $\begin{array}{l}\text { clay } \\
(\%)\end{array}$ \\
\hline & & $6-9$ & $\begin{array}{c}10 \mathrm{YR} \\
3 / 2\end{array}$ & 5.6 & 1.1 & 6.1 & & 48.4 & 0.47 & 33 & 63 & 4 \\
\hline & $3 \mathrm{CB}$ & $9-20$ & $\begin{array}{l}1 Y \\
4 / 5\end{array}$ & 5.9 & 0.0 & 1.0 & & 9.4 & 0.20 & 68 & 28 & 4 \\
\hline & $3 \mathrm{C}$ & $20-60+$ & $\begin{array}{l}2.5 \mathrm{Y} \\
4.5 / 3\end{array}$ & 6.6 & 0.3 & 0.5 & & 9.3 & 0.18 & 70 & 25 & 5 \\
\hline \multirow[t]{4}{*}{ No. 8} & $\begin{array}{c}\mathrm{Oi} \\
\mathrm{Oa} / \mathrm{Oe}\end{array}$ & $\begin{array}{c}0.5-0 \\
0-2\end{array}$ & $\begin{array}{c}10 \mathrm{YR} \\
2 / 2\end{array}$ & 5.7 & 0.0 & & 47.2 & & & & & \\
\hline & $\mathrm{A}$ & $2-6$ & $\begin{array}{c}10 \mathrm{YR} \\
3 / 3\end{array}$ & 5.1 & 0.3 & 5.6 & & 29.9 & 0.34 & 63 & 34 & 3 \\
\hline & $\mathrm{CA}$ & $6-19$ & $\begin{array}{c}2.5 \mathrm{Y} \\
4 / 4\end{array}$ & 5.6 & 1.0 & 1.8 & & 9.4 & 0.14 & 72 & 35 & 3 \\
\hline & $\mathrm{C}$ & $19-45+$ & $\begin{array}{l}5 \mathrm{Y} \\
4 / 1\end{array}$ & 5.9 & 0.0 & 0.4 & & 5.6 & 0.09 & 76 & 20 & 4 \\
\hline \multirow[t]{4}{*}{ No. 9} & & & $\begin{array}{c}10 \mathrm{YR} \\
3 / 1\end{array}$ & 7.1 & 0.3 & 6.1 & & 27.4 & & & & \\
\hline & $\mathrm{C}$ & $8-45$ & $\begin{array}{c}2.5 \mathrm{Y} \\
4 / 2\end{array}$ & 7.5 & 1.7 & 1.4 & & 14.0 & 0.13 & 42 & 50 & 8 \\
\hline & $\mathrm{Cg}$ & $45-55$ & $\begin{array}{l}5 \mathrm{Y} \\
4 / 1\end{array}$ & 7.2 & 1.2 & 1.2 & & 10.4 & 0.07 & 29 & 66 & 5 \\
\hline & $2 \mathrm{Cg} 2$ & $55-65+$ & $\begin{array}{c}10 \mathrm{YR} \\
4 / 5\end{array}$ & 7.2 & 0.1 & 0.4 & & 7.8 & 0.18 & 43 & 51 & 6 \\
\hline \multirow[t]{3}{*}{ No. 10} & $\begin{array}{l}\mathrm{Oi} \\
\mathrm{Oe}\end{array}$ & $\begin{array}{l}2-0 \\
0-5\end{array}$ & $\begin{array}{c}10 \mathrm{YR} \\
2 / 1\end{array}$ & 5.0 & 1.4 & & 52.1 & & 0.33 & & & \\
\hline & $\mathrm{Ah}$ & $5-21$ & $\begin{array}{c}10 \mathrm{YR} \\
3 / 3\end{array}$ & 4.5 & 0.6 & 6.4 & & 49.1 & 0.40 & 40 & 45 & 15 \\
\hline & $\mathrm{CA}$ & $21-65+$ & $\begin{array}{c}2.5 \mathrm{Y} \\
4 / 4\end{array}$ & 5.8 & 0.0 & 1.5 & & 17.6 & 0.15 & 62 & 25 & 13 \\
\hline \multirow[t]{4}{*}{ No. 11} & $\begin{array}{l}\mathrm{Oi} \\
\mathrm{Oe}\end{array}$ & $\begin{array}{l}2-0 \\
0-2\end{array}$ & 10YR & 6.0 & 0.0 & & 45.0 & & & & & \\
\hline & A & $2-7$ & $\begin{array}{c}10 \mathrm{YR} \\
3 / 2\end{array}$ & 5.7 & 0.0 & 13.6 & & 72.9 & 0.24 & 31 & 55 & 14 \\
\hline & $\mathrm{AB}$ & $7-16$ & $\begin{array}{c}10 \mathrm{YR} \\
3 / 3\end{array}$ & 5.4 & 0.5 & 2.4 & & 30.5 & 0.30 & 49 & 37 & 14 \\
\hline & Bw & $16-60$ & $\begin{array}{c}10 \mathrm{YR} \\
4 / 4\end{array}$ & 5.8 & 0.2 & 2.1 & & 33.7 & 0.37 & 45 & 40 & 15 \\
\hline
\end{tabular}

do not meet the diagnostic requirements of the different taxonomic systems for typical spodic (podzolic) B horizons. Only in the Northern District, profiles No. 1 and 2 show a marked increase in non-crystalline and poorly crystalline iron (Feox) and aluminium (Alox) with depth, probably as a result of the more abundant rainfall in the area.

\subsection{Trace Elements}

In order to assess the geochemical content of each individual soil sample and its possible contamination, values must be referred to average values, to the parent material background and to thresholds. Unfortunately, the mean and range concentrations of trace elements in soils proposed in the literature are significantly divergent (Allaway 1968; Kabata-Pendias, Pendias 1984, 2001; 
Tab. 4 - Reports concentrations of six trace elements in Northern and Eastern district soil profiles

\begin{tabular}{|c|c|c|c|c|c|c|c|c|}
\hline \multicolumn{9}{|c|}{ NORTHERN DISTRICT } \\
\hline Profile & Horizon & $\begin{array}{c}\text { Depth } \\
\text { (cm) }\end{array}$ & $\begin{array}{c}\mathrm{Cu} \\
\mathrm{mg} \mathrm{kg}^{-1}\end{array}$ & $\begin{array}{c}\mathrm{Cr} \\
\mathrm{mg} \mathrm{kg}^{-1} \\
\end{array}$ & $\begin{array}{c}\mathrm{Pb} \\
\mathrm{mg} \mathrm{kg}^{-1}\end{array}$ & $\begin{array}{c}\mathrm{Zn} \\
\mathrm{mg} \mathrm{kg}^{-1}\end{array}$ & $\begin{array}{c}\mathrm{Cd} \\
\mathrm{mg} \mathrm{kg}^{-1}\end{array}$ & $\begin{array}{c}\mathrm{Ni} \\
\mathrm{mg} \mathrm{kg}^{-1}\end{array}$ \\
\hline No. 1 & $\begin{array}{l}\mathrm{Ah} \\
\mathrm{BA} \\
\mathrm{C} / \mathrm{R}\end{array}$ & $\begin{array}{c}0-10 \\
10-40 \\
40-50+\end{array}$ & $\begin{array}{l}59.2 \\
66.3\end{array}$ & $\begin{array}{l}40.8 \\
44.2\end{array}$ & $\begin{array}{l}159.2 \\
70.3\end{array}$ & $\begin{array}{l}116.3 \\
128.5\end{array}$ & $\begin{array}{l}0.51 \\
0.46\end{array}$ & $\begin{array}{l}34.7 \\
40.2\end{array}$ \\
\hline No. 2 & $\begin{array}{c}\mathrm{A} \\
\mathrm{AC} \\
2 \mathrm{C} \\
\end{array}$ & $\begin{array}{c}0-20 \\
20-60 \\
60-80+ \\
\end{array}$ & $\begin{array}{l}90.9 \\
95.7\end{array}$ & $\begin{array}{l}122.5 \\
222.7\end{array}$ & $\begin{array}{l}59.3 \\
56.6\end{array}$ & $\begin{array}{l}90.9 \\
87.9\end{array}$ & $\begin{array}{l}0.04 \\
\text { b.d.l. }\end{array}$ & $\begin{array}{l}112.7 \\
197.3\end{array}$ \\
\hline No. 3 & $\begin{array}{c}\mathrm{Oe} \\
\mathrm{Ah} \\
\mathrm{BA} \\
\mathrm{C} \\
\end{array}$ & $\begin{array}{c}5-0 \\
0-10 / 15 \\
10 / 15-25 / 30 \\
25 / 30-50+ \\
\end{array}$ & $\begin{array}{l}39.5 \\
40.0\end{array}$ & $\begin{array}{l}27.7 \\
18.0\end{array}$ & $\begin{array}{l}33.6 \\
32.0\end{array}$ & $\begin{array}{l}63.2 \\
54.0\end{array}$ & $\begin{array}{l}0.14 \\
0.02\end{array}$ & $\begin{array}{l}25.7 \\
20.0\end{array}$ \\
\hline \multicolumn{9}{|c|}{ EASTERN DISTRICT } \\
\hline No. 4 & $\begin{array}{c}\text { Ah1 } \\
\text { Ah2 } \\
2 \mathrm{~A} \\
2 \mathrm{Bw} \\
2 \mathrm{CB}\end{array}$ & $\begin{array}{c}0-9 \\
9-15 \\
15-38 \\
38-58 \\
58-75+\end{array}$ & $\begin{array}{l}47.0 \\
51.4 \\
57.5 \\
36.3 \\
47.4\end{array}$ & $\begin{array}{l}48.8 \\
67.2 \\
65.5 \\
54.4 \\
59.3\end{array}$ & $\begin{array}{l}38.3 \\
41.5 \\
41.7 \\
36.3 \\
35.6\end{array}$ & $\begin{array}{l}95.8 \\
88.9 \\
87.3 \\
96.8 \\
98.8 \\
\end{array}$ & $\begin{array}{l}0.16 \\
0.16 \\
0.16 \\
0.01 \\
0.02\end{array}$ & $\begin{array}{l}29.6 \\
33.6 \\
37.7 \\
30.2 \\
35.6\end{array}$ \\
\hline No. 5 & $\begin{array}{c}\mathrm{Oi} \\
\mathrm{Oe} \\
\mathrm{Oa} \\
\mathrm{Ah} 1 \\
2 \mathrm{Ah} 2 \\
2 \mathrm{AC} \\
2 \mathrm{C} \\
\end{array}$ & $\begin{array}{c}0.5-0 \\
0-3 \\
3-6 \\
6-12 \\
12-40 \\
40-55 \\
55-75+ \\
\end{array}$ & $\begin{array}{l}40.0 \\
42.2 \\
49.2 \\
59.4\end{array}$ & $\begin{array}{l}38.0 \\
46.2 \\
53.1 \\
57.5\end{array}$ & $\begin{array}{l}34.0 \\
32.1 \\
39.4 \\
40.2\end{array}$ & $\begin{array}{l}106.0 \\
84.3 \\
65.0 \\
63.2\end{array}$ & $\begin{array}{l}0.60 \\
0.22 \\
0.08 \\
0.04\end{array}$ & $\begin{array}{l}18.0 \\
24.1 \\
25.6 \\
34.5\end{array}$ \\
\hline No. 6 & $\begin{array}{l}\mathrm{Oi} \\
\mathrm{Oa} \\
\mathrm{Ah} \\
\mathrm{AB} \\
2 \mathrm{R} \\
\end{array}$ & $\begin{array}{c}0.5-0 \\
0-2 \\
2-4 \\
4-24 \\
24-45+ \\
\end{array}$ & $\begin{array}{l}52.0 \\
64.0\end{array}$ & $\begin{array}{l}50.0 \\
52.0\end{array}$ & $\begin{array}{l}44.0 \\
44.0\end{array}$ & $\begin{array}{l}108.0 \\
82.0\end{array}$ & $\begin{array}{l}0.40 \\
0.02\end{array}$ & $\begin{array}{l}28.0 \\
36.0\end{array}$ \\
\hline No. 7 & $\begin{array}{c}\mathrm{Oi} \\
\mathrm{Oa} \\
\mathrm{Ah} \\
2 \mathrm{~A} \\
3 \mathrm{CB} \\
3 \mathrm{C} \\
\end{array}$ & $\begin{array}{c}0.5-0 \\
0-3 \\
3-6 \\
6-9 \\
9-20 \\
20-60+ \\
\end{array}$ & $\begin{array}{l}22.4 \\
\\
42.0 \\
66.1 \\
82.3 \\
\end{array}$ & $\begin{array}{l}13.3 \\
\\
60.0 \\
81.7 \\
74.3 \\
\end{array}$ & $\begin{array}{l}20.4 \\
\\
54.0 \\
33.1 \\
52.2 \\
\end{array}$ & $\begin{array}{l}41.8 \\
\\
70.0 \\
83.7 \\
80.3 \\
\end{array}$ & $\begin{array}{l}0.15 \\
\\
0.08 \\
0.06 \\
0.20 \\
\end{array}$ & $\begin{array}{c}8.2 \\
\\
22.0 \\
40.9 \\
40.2 \\
\end{array}$ \\
\hline No. 8 & $\begin{array}{c}\mathrm{Oi} \\
\mathrm{Oa} / \mathrm{Oe} \\
\mathrm{A} \\
\mathrm{CA} \\
\mathrm{C}\end{array}$ & $\begin{array}{c}0.5-0 \\
0-2 \\
2-6 \\
6-19 \\
19-45+\end{array}$ & $\begin{array}{c}48.2 \\
88.4 \\
101.5\end{array}$ & $\begin{array}{c}88.4 \\
100.4 \\
92.0\end{array}$ & $\begin{array}{l}36.1 \\
24.1 \\
26.8\end{array}$ & $\begin{array}{l}74.3 \\
62.2 \\
44.1\end{array}$ & $\begin{array}{l}\text { b.d.l. } \\
\text { b.d.l. } \\
\text { b.d.l. }\end{array}$ & $\begin{array}{l}42.2 \\
42.2 \\
40.2\end{array}$ \\
\hline No. 9 & $\begin{array}{c}\mathrm{Ap} \\
\mathrm{C} \\
\mathrm{Cg} \\
2 \mathrm{Cg} 2\end{array}$ & $\begin{array}{c}0-8 \\
8-45 \\
45-55 \\
55-65+\end{array}$ & $\begin{array}{l}73.4 \\
84.0 \\
58.7\end{array}$ & $\begin{array}{l}85.3 \\
74.0 \\
62.5\end{array}$ & $\begin{array}{l}35.7 \\
34.0 \\
26.5\end{array}$ & $\begin{array}{l}59.5 \\
64.0 \\
47.3\end{array}$ & $\begin{array}{l}0.04 \\
0.08 \\
0.04\end{array}$ & $\begin{array}{l}41.7 \\
46.0 \\
32.2\end{array}$ \\
\hline No. 10 & $\begin{array}{l}\mathrm{Oi} \\
\mathrm{Oe} \\
\mathrm{Ah} \\
\mathrm{CA}\end{array}$ & $\begin{array}{c}2-0 \\
0-5 \\
5-21 \\
21-65+\end{array}$ & $\begin{array}{l}43.1 \\
56.0 \\
88.5\end{array}$ & $\begin{array}{l}27.5 \\
54.1 \\
51.9\end{array}$ & $\begin{array}{l}49.0 \\
54.1 \\
65.4\end{array}$ & $\begin{array}{l}58.8 \\
67.6 \\
65.4\end{array}$ & $\begin{array}{l}0.22 \\
0.10 \\
0.02\end{array}$ & $\begin{array}{l}19.6 \\
25.1 \\
25.0\end{array}$ \\
\hline No. 11 & $\begin{array}{c}\mathrm{Oi} \\
\mathrm{Oe} \\
\mathrm{A} \\
\mathrm{AB} \\
\mathrm{Bw}\end{array}$ & $\begin{array}{c}2-0 \\
0-2 \\
2-7 \\
7-16 \\
16-60\end{array}$ & $\begin{array}{l}43.3 \\
61.1 \\
55.8\end{array}$ & $\begin{array}{l}53.1 \\
61.1 \\
78.8\end{array}$ & $\begin{array}{l}39.4 \\
43.9 \\
38.5\end{array}$ & $\begin{array}{l}84.6 \\
78.2 \\
92.3\end{array}$ & $\begin{array}{l}0.18 \\
0.17 \\
0.04\end{array}$ & $\begin{array}{l}23.6 \\
36.3 \\
40.4\end{array}$ \\
\hline
\end{tabular}


Gladney, Burns1985; Canepa et al. 1994; Baize 1997; Helmke 2000). Another factor of uncertainty is the lack of information in many papers on the form of occurrence of the trace elements in question: total, available, mobile, etc.

Moreover, data on relative mobilities through soil profiles are sometimes discordant, particularly those for $\mathrm{Cu}$ and $\mathrm{Ni}$ (Brooks 1983; Kabata-Pendias, Pendias 1984, 2001; Fujikawa et al. 2000). Only $\mathrm{Pb}$ and $\mathrm{Cr}$ are generally agreed to have very low mobility in the acid conditions of a supergene environment. Moreover, sampling and laboratory extraction methods greatly influence and complicate the interpretation of results (Tobias et al. 1997).

In addition, note that it is very difficult to establish geochemical background levels in periglacial environments, where the bedrock is covered with till, loess, fluvioglacial and fluvial deposits, and where soils have a cumulative character (Birkeland 1999). In such environments it is meaningless to consider trace element contents in the bedrock as background values. Moreover, neither the present depth of the bedrock nor the possible effects of past or active weathering and pedogenesis in the study area are well known. In recently active mountain ranges which experienced Alpine orogenesis, the products of intense physical weathering and continuous slope degradation overlap with debris flow, creep, cryoclastism and freeze-thaw processes, etc. Such processes may mask heavy metal translocation in soil profiles. Lastly, aeolian silt partly covers some soil parent materials.

For all these reasons, the present work adopted world soil average elemental contents as background and reference values (Tab. 4).

In the Northern District, Cd concentrations are low in all profiles except profile No. 1, where it is slightly over the world mean value. Cr is particularly abundant in profile No. 2, which also has high $\mathrm{Ni}$ and $\mathrm{Cu}$ concentrations. These high values testify to the genetic diversity of the parent materials of profile No. 2 with respect to the parent materials of other profiles in the district. Moreover, the different values within the same profile also highlight the internal genetic diversity between the two materials themselves. In short, profile No. 2, developed in a loess-like material which covered alluvial deposits, stands out from the others for its higher $\mathrm{Cr}, \mathrm{Cu}$, and $\mathrm{Ni}$ contents.

As for $\mathrm{Pb}$, since this element has a very low mobility, its position in a profile can effectively indicate its atmospheric or lithological origin. In profile No. 1, the higher $\mathrm{Pb}$ contents and the fair amounts of $\mathrm{Zn}$ and $\mathrm{Cd}$ in the surface horizons indicate that these elements probably derived from an atmospheric source.

Cd shows an irregular distribution in all Eastern District soil profiles; it exceeds the world mean value only in the surface horizon of profile No. 5 . Cr slightly increases with depth at all sites and has a very low mobility; it was likely inherited from the parent materials.

$\mathrm{Ni}$ and $\mathrm{Cu}$, generally known to be easily mobilized during weathering, are nearly constantly present in high quantities at depth.

Since $\mathrm{Zn}$ is quite mobile, its high concentrations in the surface horizons of profiles No. 4, 5, 6 and 8 suggest the local contribution of atmospheric fallout.

Lastly, the so-called reference A-values (target values) and C-values (intervention values), calculated on the weighted average of whole profiles, were compared (Fig. 4) to trace element contents in the soils of the two districts following the procedure of the Dutch National Institute of Public Health and Environmental Protection (1991). This system of risk evaluation adequately takes into account the actual clay and organic matter content in soil, since these components are able to inactivate contaminants. 

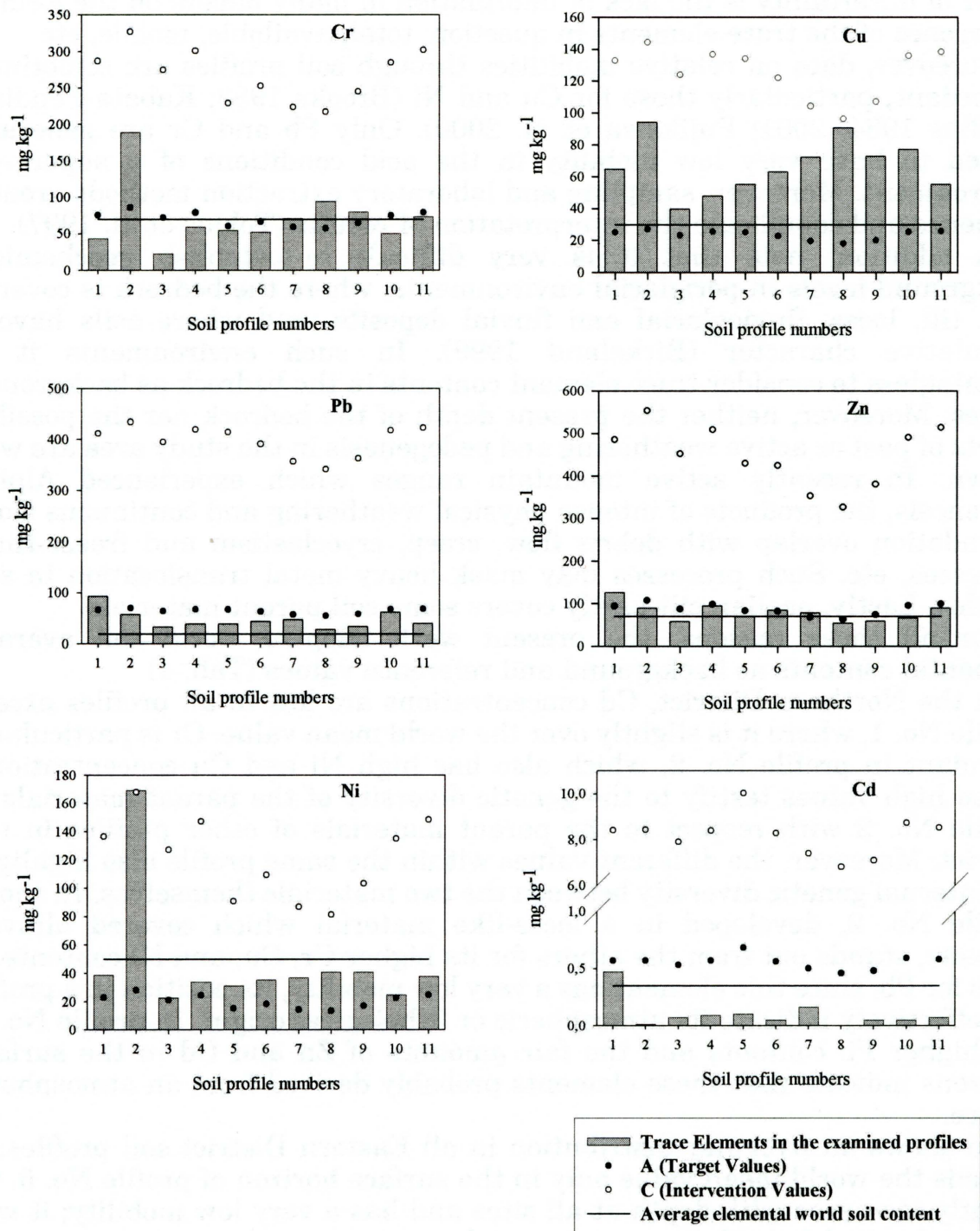

Fig. 4 - Weighted averages of trace element contents in whole profiles of investigated soils compared with the average world soil elemental concentrations (Logan 2000) and with the Target (A) and Intervention (C) values calculated according to the procedure of the Dutch National Institute of Public Health and Environmental Protection (1991)

$\mathrm{Cd}, \mathrm{Pb}$ and $\mathrm{Zn}$ concentrations are commonly within the limits of the $\mathrm{A}$ value, while $\mathrm{Cu}$ contents were everywhere above the $\mathrm{A}$ value. $\mathrm{Cr}$ and $\mathrm{Ni}$ concentrations were particularly high in profile No. 2 . When referred to the $\mathrm{C}$ values, $\mathrm{Pb}, \mathrm{Cr}, \mathrm{Cd}$ and $\mathrm{Zn}$ concentrations were everywhere well below values of ecotoxicological risk. Ni reaches the $\mathrm{C}$ threshold of $168 \mathrm{mg} \mathrm{kg}-1$ in profile No. 2, and $\mathrm{Cu}$ the threshold of $90 \mathrm{mg} \mathrm{kg-1}$ in site No. 8 . 


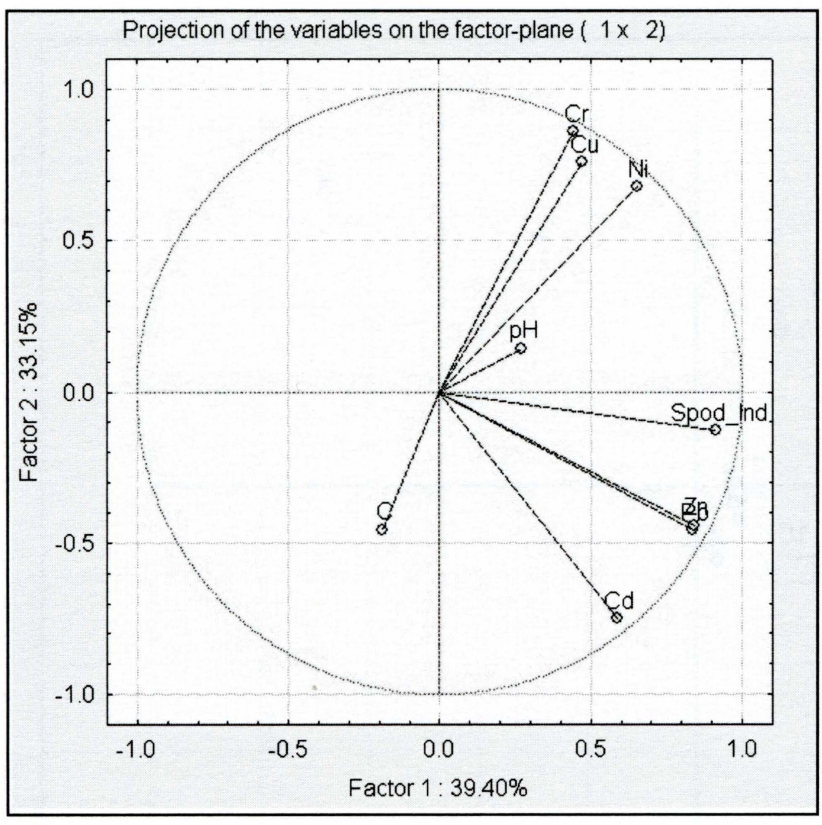

Fig. 5 - PCA of soil profile variables (weighted averages in the $0-30 \mathrm{~cm}$ depth range). Spod-Ind. - Spodicity Index (SI), C - Organic Carbon

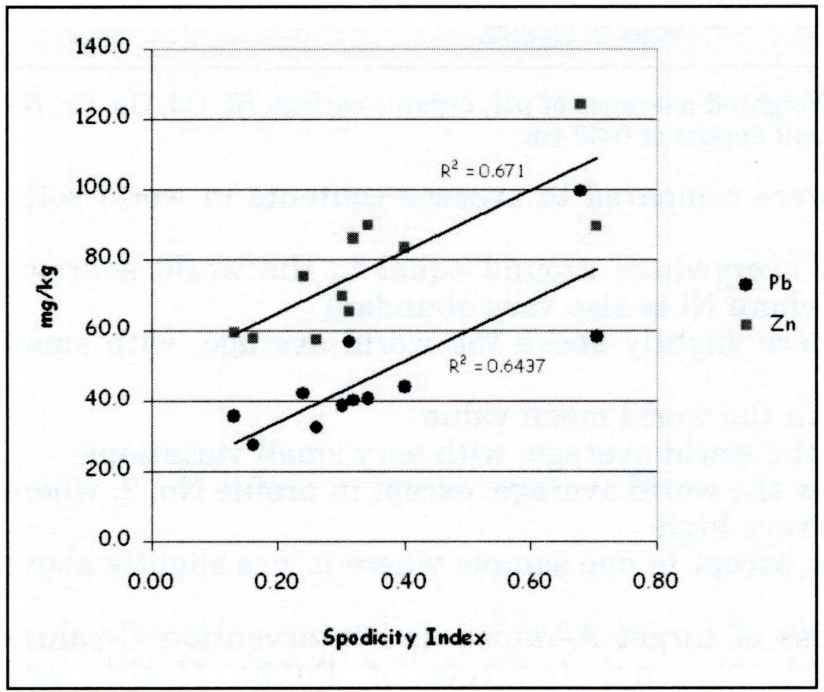

Fig. 6 - Correlation between $\mathrm{Pb}-\mathrm{Zn}$ and the Spodicity Index
Principal Components Analysis (PCA) applied to the main soil parameters (Fig. 5) highlighted two groups of variables: $\mathrm{Cr}, \mathrm{Cu}$ and $\mathrm{Ni}$ are linked to $\mathrm{pH}$, whereas $\mathrm{Cd}, \mathrm{Pb}$ and $\mathrm{Zn}$ are linked to SI. These relationships were also confirmed by the high statistical correlation between the variables.

It is highly meaningful $(p<0.005)$ the correlation (Fig. 6) between $\mathrm{Pb}$, $\mathrm{Zn}$ and the SI. These elements were concentrated likely in chelate forms, within the illuvial horizons with higher SI, as well as frequently mentioned in literature (Sartori et al. 2002). PCA applied to soil profiles (Fig. 7) shows that the soils of the Eastern District (Profiles No. 4 up to 11) are quite similar among themselves, whereas the soils of the Northern one are rather unlike, probably because more influenced by the geochemical variability of the parent material.

\section{Conclusions}

The first part of this paper showed how melanization prevails over podzolization in the surveyed region. Although the lithological characteristics of many acidic rocks, climate conditions and even altitude apparently favour the latter process, aeolian contributions in the Holocene and Pleistocene seem to have left on soils important marks of steppe pedoenvironments.

The second part examined trace elements contents and their ecotoxicity thresholds. Contents in the examined soils, as weighted averages in all the 


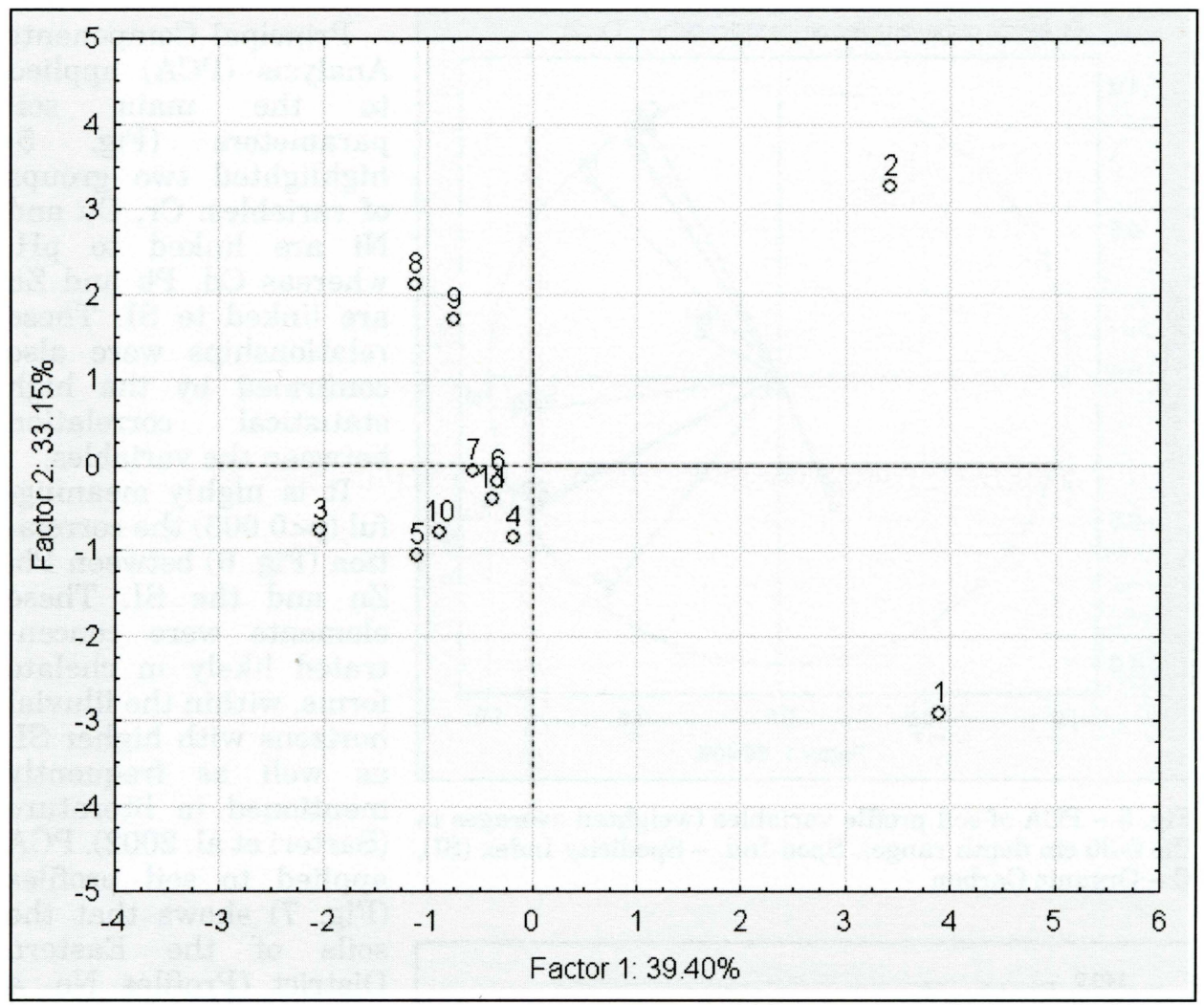

Fig. 7 - PCA for soil profiles. Weighted averages of $\mathrm{pH}$, organic carbon, $\mathrm{SI}, \mathrm{Cd}, \mathrm{Cu}, \mathrm{Cr}, \mathrm{Ni}$, $\mathrm{Pb}$ and $\mathrm{Zn}$ were calculated for soil depths of $0-30 \mathrm{~cm}$

horizons of each profile, were compared to average contents in world soils. Results were as follows:

- Cr concentrations were everywhere around equal to the world average, except in profile No. 2, where Ni is also very abundant

- $\mathrm{Pb}$ was almost everywhere slightly above the world average, with small deviations

- Cu was fairly higher than the world mean value

- Zn was almost equal to the world average, with very small variations

- Ni was everywhere below the world average, except in profile No. 2 , where the $\mathrm{Cr}$ content was also very high

- Cd was generally scarce, except in one sample where it was slightly above average.

Possible values in excess of target A-values and intervention $\mathrm{C}$-values established by the Dutch National Institute of Public Health and Environmental Protection (1991) were then examined. The thresholds were calculated taking into consideration clay and organic matter contents in the examined soil. Results show that $\mathrm{Cr}$ is everywhere much lower than intervention $\mathrm{C}$-values, $\mathrm{Cu}$ contents range between $\mathrm{A}$ and $\mathrm{C}$-values, $\mathrm{Pb}$ and $\mathrm{Cd}$ contents are generally lower than A-values, and $\mathrm{Zn}$ concentrations oscillate above and below A-values, as do Ni contents (except in profile No. 2). 
Based on trace elements contents, we conclude that the investigated soils generally show no significant contamination. The higher metal concentrations in soil profile No. 2 (developed from aeolian silt covering alluvial deposits) are probably due to contributions from distant areas which cannot be identified on the basis of collected data. This presumption is based on location of soil profile No. 2 in relation to the walley orientation and dominant wind direction and demands additional sampling in order to prove it.

\section{References:}

ABDULIN, A. A., AFONICHEV, N. A., VLASOV, N. G., DOVZHIKOV, A. E., KLEIMAN, G. P., TULYAGANOV, K. TH., KHAMRABAEV, I. KH., CHAKABAYEV, S. E., SHLYGIN, A. E. (1984): Geology of Kazakhstan and Central Asia: In: Publishing Office Nauka: Geology of the URSS, Colloquium 01, Reports, 1. Moskow, 325 pp.

ALLAWAY, W. H. (1968): Agronomic controls over the environmental cycling of trace elements. Advances in Agronomy, 20, pp. 235-274.

BAIZE, D. (1997) : Teneurs totales en éléments traces métalliques dans les sols (France). INRA, Paris, $406 \mathrm{p}$.

BETTINELLI, M., BEONE, G. M., SPEZIA, S., BAFFI, C. (2000): Determination of heavy metals in soil and sediments by microwave-assisted digestion and inductively coupled plasma optical emission spectroscopy analysis. Analytica Chimica Acta, 424, pp. 289-296.

BIRKELAND, P. W. (1999): Soils and Geomorphology. Oxford University Press, New York, $430 \mathrm{p}$.

BROOKS, R. R. (1983): Biological Methods of Prospecting for Minerals. John Wiley \& Sons, New York, $313 \mathrm{p}$.

CANEPA, D., IZZA, C., FACCO, S. (1994): Metalli pesanti. In Min. Ris. Agr. Alim. For. \& Oss. Naz. Ped. Qual. Suolo (eds): Metodi Ufficiali di Analisi Chimica del Suolo, Roma, pp. 87-93.

COMOLLI, R., PREVITALI, F., ŠEFRNA, L. (2003): Soil development along two altitudinal transects from north-west to south-east of the Issyk Kul Lake (Northern and Central Tjan-Shan, Kazakhstan-Kyrgyzstan). Geografia Fisica e Dinamica Quaternaria, 26, pp. 111-124.

Dutch National Institute of Public Health and Environmental Protection (1991): Risk assessment of contaminated soil. Implementation of the Soil Protection Act: Proposal for adjusted, toxicologically based Dutch C-values for metals and arsenic. Laboratory of Soil and Groundwater Research (The Netherlands).

FAO (2006): Guidelines for soil description. Fourth edition, 32 p., FAO, Rome, 97 pp.

FUJIKAWA, Y., FUKUI, M., KUDO, A. (2000): Vertical distribution of trace metals in natural soil horizons from Japan. Part 1. Effect of soil types. Water, Air and Soil Pollution, 124, pp. 1-21.

GLADNEY, E. S., BURNS, C. E. (1985): Compilation of elemental concentration data for samples SO-1 to SO-4. Geostand. Newsl., 9, pp. 38-43.

HELMKE, P. A. (2000): The Chemical Composition of Soils. In: Sumner, M. E. (ed.): Handbook of Soil Science. CRC Press, Boca Raton, Florida, pp. B3-B24.

IUSS Working Group WRB (2006): World reference base for soil resources 2006. World Soil Resources Reports No. 103. FAO, Rome, 145 p.

KABATA-PENDIAS, A., PENDIAS, H. (1984): Trace Elements in Soils and Plants. CRC Press, Boca Raton, Florida, 315 p.

KABATA-PENDIAS, A., PENDIAS, H. (2001) : Trace Elements in Soils and Plants. CRC Press, Boca Raton, Florida, 413 p.

LOGAN, T. J. (2000): Soils and Environmental Quality. In: Sumner, M. E. (ed.): Handbook of Soil Science. CRC Press, Boca Raton, Florida, pp. G155-G169.

Ministero delle Politiche Agricole e Forestali (2000): Metodi di Analisi Chimica dei Suoli. In: Violante, P., Sequi, P. (eds.): Collana di Metodi Analitici per l'Agricoltura. Franco Angeli, Milano, pp. 1-474.

Ministry of Geology of SSSR (1983): Geological Map of the USSR and Adjoining Water 
Covered Areas. Scale 1:2 500 000. Moscow

Munsell Soil Color Chart (2000): Revised Washable Edition. Munsell Color, New York.

PREVITALI, F., ASSI, I., ŠEFRNA, L. (1997): Pedosequences in Northern Tian Shan mountain belt (Kazakhstan and Kirgizstan). Geografia Fisica e Dinamica Quaternaria, 20, pp. 157-167.

SARTORI, G., CORRADINI, F., BINI, C., GEMIGNANI, S., MANCABELLI, A. (2002): Contenuto di metalli pesanti nei suoli del Trentino. Studi Trentini di Scienze Naturali Acta Geologica, 79, pp. 75-117.

TIBALDI, A., GRAZIOTTO, E., FORCELLA, F., GAPICH, V. U. (1997): Morphotectonic indicators of Holocene faulting in Central Tian-Shan, Kazakstan, and geodynamic implications. Journal of Geodynamics, 23, pp. 23-45.

TOBIAS, F. J., BECH, J., SANCHEZ ALGARRA, P. (1997): Statistical approach to discriminate background and anthropogenic input of trace elements in soils of Catalonia, Spain. Water, Air, and Soil Pollution, 100, pp. 63-78.

\section{Shrnutí}

\section{STOPOVÉ PRVKY V PU゚DÁCH V SEVERNÍ A CENTRÁLNÍ ČÁSTI POHOŘÍ TIAN- SHAN (KAZACHSTÁN - KYRGYSTÁN)}

V rámci dvou vzájemně navazujících expedicí byly zkoumány půdy v oblasti severozápadně a jihovýchodně od jezera Issyk-Kul v centrálním Tjan-Sanu (Kazachstán a Kyrgystán). Půdy byly sledovány podél dvou transektů zahrnujících rozmezí nadmořských výšek 2000 až $3500 \mathrm{~m}$. Souvislosti mezi půdami, klimatickými podmínkami, vegetací a reliéfem byly předmětem předchozích prací, tato je zaměřena na posouzení obsahu stopových prvků v půdě jako indikátoru možné kontaminace půd ve vysokých nadmořských výškách. Ta je zpravidla důsledkem jejich dálkového atmosferického přenosu.

Terénní popis půdních profilů a jejich polohy byl proveden podle směrnic FAO, barva půdy určena pomocí Munsellovy barevné škály a typologická klasifikace podle WRBS. Odebrané půdní vzorky byly analyzovány v souladu s metodickými postupy italského Ministerstva pro zemědělskou a lesnickou politiku. Po úpravě na jemnozem $2 \mathrm{~mm}$ byly ve vzorcích stanoveny $\mathrm{pH} / \mathrm{H} 2 \mathrm{O}$, Corg., kationtová výměnná kapacita (CEC), obsah karbonátů, Feox a Alox $\mathrm{k}$ výpočtu indexu spodicity - SI (Alox+1/2Feo x). Pipetovací metodou byla určena zrnitost. Tzv. pseudototální formy stopových prvků $\mathrm{Cd}, \mathrm{Cr}, \mathrm{Cu}, \mathrm{Zn}, \mathrm{Pb}$ a Ni byly stanoveny ve výluhu lučavky královské podle postupu Bettinelliho metodou FAAS.

Polohu, environmentální data a půdně typologickou klasifikaci sledovaných profilů uvádí tabulka 2, základní chemické vlastnosti půd jsou uvedena v tabulce 3. Získaná data a laboratorní výsledky ukazují, že kvartérní procesy tvorby pơd podobné melanizaci, zodpovědné za vznik současných stepních černozemí, jsou aktivní i ve velmi vysokých nadmořských výškách. Tyto procesy pravděpodobně podporuje přítomnost spraším podobného eolického překryvu a specifických klimatických podmínek.

V obou sledovaných oblastech nesplňují horizonty B diagnostická kritéria různých taxonomických systémů pro typické spodické (podzolové) B horizonty. Pouze v oblasti severně od jezera Issyk-Kul vykazují profily č. 1 a 2 s hloubkou stoupající obsah Feox a Alox, pravděpodobně jako důsledek vyšších srážek v tomto území.

Geochemické hodnocení jednotlivých půdních vzorků a odhad jejich možné kontaminace vyžaduje porovnání s průměrnými hodnotami, pozadím výchozího materiálu a prahovými obsahy. Vzhledem ke skutečnosti, že literární údaje jak o koncentracích stopových prvků, tak jejich formách a mobilitě v rámci půdních profilů se často liší, interpretace výsledků je také výrazně ovlivňována různým způsobem vzorkování a metodami laboratorní extrakce a navíc je velmi obtížné určit geochemické pozadí v periglaciálních podmínkách, kde je podklad překryt jílem, spraší, fluvioglaciálními a fluviálními sedimenty a kde mají pủdy kumulativní charakter, byly $\mathrm{v}$ této práci jako pozadí a referenční hodnoty použity průměrné obsahy prvků v půdách světa (obr. 4). Koncentrace 6 sledovaných stopových prvků v půdách zájmového území uvádí zvlášt pro oblast severní a východní tabulka 4 .

V severní části byly koncentrace Cd nízké ve všech profilech s výjimkou profilu č. 1 , kde mírně převyšují světový průměr. U profilu č. 2 vyvinutého ze sprašového substrátu překrytého alluviálními sedimenty byla zaznamenána zvýšená koncentrace $\mathrm{Cr}, \mathrm{Ni}$ a $\mathrm{Cu}$.

$\mathrm{U} \mathrm{Pb}$ lze, vzhledem $\mathrm{k}$ velmi nízké mobilitě, usuzovat $\mathrm{z}$ distribuce tohoto prvku v rámci profilu na jeho atmosférický nebo litologický původ. V profilu č. 1, indikuje vyšší obsah $\mathrm{Pb}$ a obsah Zn a Cd v povrchových horizontech pravděpodobný atmosférický zdroj. 
Cd vykazuje ve všech profilech východní oblasti nepravidelnou distribuci; světový průměr přesahuje pouze $\mathrm{v}$ povrchovém horizontu profilu č. 5 . Obsah $\mathrm{Cr}$ se mírně zvyšuje $\mathrm{s}$ hloubkou a na všech lokalitách vykazuje velmi nízkou mobilitu, lze tedy usuzovat na jeho geogenní původ. $\mathrm{Ni}$ a $\mathrm{Cu}$, které jsou všeobecně pokládány za prvky lehce uvolnitelné v procesu zvětrávání, jsou téměř konstantně přítomny ve vyšším množství $v$ hlouběji položených horizontech. Jelikož Zn je vcelku mobilním prvkem, je jeho vyšší koncentrace v povrchových horizontech profilů 4, 5, 6 a 8 přičítána atmosferickému spadu.

Vážené průměry obsahu stopových prvků $\mathrm{v}$ celých sledovaných profilech byly porovnány $\mathrm{s}$ průměrem koncentrace těchto prvků $\mathrm{v}$ půdách světa a $\mathrm{s}$ tzv. referenčními hodnotami $\mathrm{A}$ (target values) a $C$ (intervention values) vypočtenými podle metody nizozemského Národního ústavu pro zdraví a ochranu životního prostředí. Tento systém hodnocení rizika bere v úvahu i aktuální obsah jílu a organické hmoty v půdách, jako složek schopných inaktivovat kontaminanty (obr. 4).

Existuje vysoce významná korelace mezi obsahem $\mathrm{Pb}, \mathrm{Zn}$ a indexem spodicity $\mathrm{SI}$ (obr. 6). Tyto prvky jsou $\mathrm{v}$ illuviálních horizontech $\mathrm{s}$ vysokým SI koncentrovány pravděpodobně v chelátových formách.

Půdy východní oblasti vykazují menší variabilitu než půdy severní oblasti, což je s největší pravděpodobností zpưsobeno geochemickou variabilitou výchozího materiálu (obr. 7).

V první části textu je poukázáno na převahu melanizace nad podzolizací ve sledované oblasti, ačkoli litologické charakteristiky mnoha kyselých hornin, klima a nadmořská výška zjevně upřednostňují druhý $\mathrm{z}$ uvedených procesů. Důvodem je přítomnost holocenních a pleistocenních eolických sedimentů.

Druhá část se zabývá obsahem stopových prvků a jejich ekotoxicitou. Obsah ve sledovaných půdách byl jako vážený průměr všech horizontů každého profilu porovnán s průměrným obsahem v půdách světa s následujícími výsledky:

- koncentrace Cr se ve všech př́ípadech téměř rovnala světovému průměru s výjimkou profilu 2, který vykazoval také vyšší obsah $\mathrm{Ni}$

- obsah $\mathrm{Pb}$ byl téměř vždy mírně nad světovým průměrem

- obsah $\mathrm{Cu}$ byl o dost vyšší než světový průměr

- koncentrace $\mathrm{Zn}$ bylatéměř rovna světovému průměru, s velmi malou variabilitou

- obsah Ni byl vždy pod úrovní světového průměru s výjimkou profilu č. 2 , kde byl stejně jako obsah Zn velmi vysoký

- př́tomnost Cd byla obecně velmi vzácná, s výjimkou jednoho vzorku, kde byla lehce nad průměrem.

Z porovnání s hodnotami A (target values) a $\mathrm{C}$ (intervention values) vyplývá, že obsah $\mathrm{Cr}$ byl ve všech případech mnohem nižší než hodnoty $\mathrm{C}$, obsah $\mathrm{Cu}$ se pohyboval mezi hodnotami $\mathrm{A}$ a $\mathrm{C}$, obsah $\mathrm{Pb}$ a $\mathrm{Cd}$ byl nižší než hodnoty $\mathrm{A}$ a koncentrace $\mathrm{Zn}$ oscilovala nad a pod hodnotami A, stejně jako obsah $\mathrm{Ni}$ (s výjimkou profilu č. 2).

$\mathrm{Na}$ základě obsahu stopových prvkŭ vyvozujeme, že sledované půdy vcelku nevykazují výraznou kontaminaci. Vyšší obsah kovů v profilu č. 2 (vyvinutém na eolickém prachu překrytém alluviálními sedimenty) je pravděpodobně důsledkem dálkového přenosu a nelze ho identifikovat na základě získaných dat. 
Obr. 1 - Geografická lokalizace zájmového území

Obr. 2 - Hlavní pohoří a řeky zájmového území. A-B a C-D jsou směry transektů

Obr. 3 - Příčný řez v profilech A-B a C-D znázorňující umístění půdních profilů

Obr. 4 - Vážené průměry obsahu stopových prvků v profilech sledovaných půd porovnané $\mathrm{s}$ průměrnými koncentracemi prvků v půdách světa (Logan 2000) a s hodnotami cílových limitů (A) a intervenčních limitů (C) podle metody Nizozemského národního ústavu pro zdraví a životní prostředí

Obr. 5 - PCA proměnných půdního profilu (vážené průměry v hloubce 0-30 cm). Spod-Ind. - Spodicity Index (SI), C - Organický uhlík

Obr. 6 - Korelace mezi $\mathrm{Pb}-\mathrm{Zn}$ a spodicity indexem

Obr. 7 - PCA pro půdní profily. Vážené průměry pro $\mathrm{pH}, \mathrm{Cox}, \mathrm{SI}, \mathrm{Cd}, \mathrm{Cu}, \mathrm{Cr}, \mathrm{Ni}, \mathrm{Pb}$ a $\mathrm{Zn} \mathrm{v}$ hloubce $0-30 \mathrm{~cm}$

Luděk Šefrna is with Department of Physical Geography and Geoecology, Faculty of Science, Charles University in Prague, Albertov 6, 128 43, Praha 2, Czechia. Franco Previtali, Roberto Comolli and Davide Cantelli are with Department of Environmental and Territorial Sciences, Earth Sciences - Geopedology, University of Milano-Bicocca, Piazza della Scienza 1, 20126 Milano, Italy. Mirjana Zdravkovič is with Institute of Soil Science, Faculty of Agriculture, University of Belgrade, Nemanjina 6, 11080 Zemun, Yugoslavia. For correspondence: sefrna@natur.cuni.cz, franco.previtali@unimib.it.

Arrived to the editorial board on January 21, 2008 